\title{
MÚSICAS DE IDA SIN REGRESO: ESTRATEGIAS Y SINERGIAS ENTRE EL CINE, EL VIDEOJUEGO Y LA INDUSTRIA DISGOGRÁFIGA EN RESIDENT EVIL
}

\author{
Josep Lluís i Falcó \\ Universitat de Barcelona / Universitat Internacional de Catalunya
}

En un mundo en el cual las fronteras se diluyen y las hibridaciones se multiplican en todos los ámbitos, existe un tipo de audiovisual (al cual muchos ni siquiera consideran como tal) que aglutina y absorbe todo aquello que le pueda proporcionar mayor espectacularidad: el videojuego. De todos ellos, algunos se han basado (directa o indirectamente) en producciones cinematográficas de las cuales han tomado en préstamo personajes, situaciones, decorados, efectos especiales y, por supuesto, la música. Numerosas bandas sonoras cinematográficas han tenido que ser adaptadas a la interactividad que ofertan ordenadores y consolas; mientras que otras, por cuestiones diversas, se han visto sustituidas por composiciones de nueva factura que, por lo general, respetan las características de su referente original.

Al mismo tiempo, y en dirección contraria, diversas han sido las producciones cinematográficas que han tomado como referente un videojuego. En junio de 2013 se cumplieron veinte años del estreno de la primera película de largometraje basada en uno (Super Mario Bros, 1993) Desde aquella, varias han sido las películas basadas en algún videojuego. No obstante, en las mismas, el referente musical del original suele desaparecer o quedar reducido a la anécdota.' La misma Super Mario Bros tenía en su BSO varios temas de música pop (muchos suenan en una secuencia que se desarrolla en una discoteca), y una partitura original de Alan Silvestri, reduciendo la presencia del tema original de Koji Kondo para el videojuego a la mínima expresión. A partir de aquí, la nula coincidencia entre los créditos musicales de los videojuegos y los de sus respectivas adaptaciones al cine se ha perpetuado, como puede verse en la Tabla 1. En la misma se comprueba, además, cómo las versiones cinematográficas nutren sus bandas sonoras musicales con temas preexistentes del ámbito pop, de los cuales se suele hacer un uso estandarizado: quedan relegadas a los momentos de mayor acción y

1 Una excepción la encontramos en Silent Hill (2009) en la cual Jeff Danna trabajó sobre la música original de Akira Kamaoka para el videojuego, apareciendo una única canción de Johnny Cash ("Ring of Fire"); esquema que se repitió en la segunda parte, Silent Hill: Revelación 3D (2012), ya que si bien el director quería que se mantuviera la música del videojuego, el contrato con la productora exigía la presencia de un compositor canadiense. 
espectacularidad (luchas y persecuciones) en clara convergencia dinámica, así como a los créditos finales, con una nula función narrativa, o bien con una presencia diegética, formando parte del decorado sonoro. ${ }^{2}$

En cuanto a sus ediciones discográficas, la notable presencia de temas de rap, metal, música electrónica, etc. sumada a la de una partitura instrumental original, provoca un lanzamiento doble (cuando no triple) del CD, con contenidos distintos. ${ }^{3} Y$ a ello deberíamos sumar la producción del correspondiente video-clip con fragmentos de la película. ${ }^{4}$ Analizar, una a una, estas películas con sus correspondientes músicas, ediciones discográficas, etc. es tarea imposible en tan poco espacio. Pero entre todas hay una saga (de videojuegos y también de películas) que se nos presenta como paradigmática de todas estas estrategias: Resident Evil.

\section{ESTRATEGIAS MUSICALES EN RESIDENT EVIL}

Resident Evil 5 es una saga de videojuegos (del género survival horror) creada por la empresa Capcom en 1996, y conocida en Japón con el nombre de Biohazard. Hasta la fecha, veinticuatro son las entregas del juego editadas, sin contar las que han aparecido solo para teléfono móvil (vid. Tabla 2); y cinco los largometrajes producidos, basados en estos videojuegos (vid. Tabla 3). De nuevo, las coincidencias musicales (en cuanto a autoría, que no en cuanto a estilo) entre unos y otros, es nula. Los ingredientes esenciales (tanto del videojuego como de las películas) son los zombis, los mutantes, la acción, la violencia y la tecnología. ${ }^{6}$ Y

2 En la versión cinematográfica de Double Dragon (1994), puede escucharse una versión de "All Togheter Now" interpretada por The Farm en los créditos finales, mientras que en Doom (2005), es la canción del grupo Nine Inch Nails "You Know What You Are?", la que cierra el film.

3 O incluso singles con alguno de los temas, como en Street Fighter (1994), cuya edición discográfica con música sobre todo de rap, se regalaba con la compra del VHS, y el tema "Straight to My Feet" de Hammer fue lanzado como single.

4 Como el del tema "I Remain" de Alanis Morissette para Prince of Persia: las arenas del tiempo (2010).

5 A partir de ahora RE cuando nos refiramos a la saga.

6 El argumento de la saga cinematográfica completa se resume de la siguiente manera: en La Colmena, un complejo subterráneo de la Corporación Umbrella, salta la alarma por peligro biológico: el Virus-T ha sido liberado. La Reina Roja (el ordenador central que lo controla todo) sella la instalación matando a todos cuanto quedan en su interior. Un comando es enviado para desactivar a la Reina Roja, y acceden a La Colmena a través de una mansión, que no es otra cosa que una tapadera. Allí encuentran a Alice (Milla Jovovich), que sufre una amnesia temporal que le impide recordar que es en realidad una agente de seguridad de Umbrella. En La Colmena deberán enfrentarse no sólo a la Reina Roja, sino a los empleados de Umbrella, ahora convertidos en zombis, infectados por el Virus-T. Alice irá recobrando la memoria y sus habilidades como agente, hasta lograr escapar junto a Matt, un activista ecologista. Ya en la superficie, es sometida a algunos experimentos durante su cuarentena, de la cual despierta encontrando la ciudad (Raccon City) en pleno caos, invadida por los zombis, y sellada por las fuerzas de Umbrella. Deberá conseguir escapar, ayudada por antiguos agentes de la corporación y, desde el exterior, por el Dr. Ashford, que les pide que rescaten a su hija que ha quedado atrapada en la ciudad. Alice se enfrenta ahora a una legión de zombis, a un poderoso mutante, Nemesis (en realidad Matt, que en la primera película fue infectado por otro mutante), y a sí misma, ya que los experimentos pretendían en realidad crear una arma humana definitiva: el Proyecto Alice. Matt y ella se acaban enfrentando, y todos logran escapar. Pasados los años, Alice vaga sola por el desierto de Nevada. Paralelamente, una caravana de supervivientes, con algunos de sus antiguos compañeros de lucha y conducida por Claire Redfield, también permanece en continuo movimiento, con la intención de llegar a Arcadia, un lugar en Alaska presuntamente no infectado por el virus. Umbrella, liderada por el siniestro Wesker, prosigue con sus experimentos en un complejo subterráneo en el mismo desierto, intentando clonar sin éxito a Alice. Se producirá un nuevo enfrentamiento para terminar con el laboratorio, y los destinos de Alice y sus compañeros se separarán momentáneamente. 
serán estos ingredientes los que condicionen las músicas utilizadas en las distintas entregas de la saga y sus ediciones discográficas, con una abundante presencia de canciones.

Roadrunner Records' lanzó la BSO de la primera entrega con el subtítulo de "Music from an inspired by the original motion picture" 8 : catorce temas que eran en su mayoría remix de otros de metal, ${ }^{9}$ dos fragmentos de diálogo, y cuatro cortes instrumentales creados por Marilyn Manson y Marco Beltrami quien, por cierto, fue obviado en los créditos del CD, probablemente también como parte de una estrategia de marketing, sin duda para potenciar la presencia de Manson (con una estética claramente empática con el tono del videojuego y el film) en el proyecto.

Éste declaraba que había diversos elementos que quería resaltar con su música: por una parte, un cierto toque infantil que venía dado por la imagen holográfica de la Reina Roja (según Manson inspirándose en el dolor de Alicia en el País de las Maravillas), mientras que la otra era el punto fascista de los comandos de la Corporación Umbrella. Para las secuencias de acción compuso temas muy violentos, con una presencia de guitarra importante, mientras que para la entrada en la Reina Roja se decantó por un vals, aunque en absoluto utilizando un lenguaje de composición clásico, al tiempo que se acercaba más a la electrónica que al metal. Éste se reservó para las secuencias de mayor acción, estableciendo así una convergencia dinámica clara. Ocurre lo mismo en Resident Evil. Apocalipsis (2004): por citar un ejemplo, cuando Alice ataca a un comando de Umbrella para poder huir de Raccon City, el ritmo frenético del montaje coincide con la música, claramente metal.

En cuanto a la banda sonora de Resident Evil: Extinción se editó en 2007, y contiene canciones de metal alternativo y metalcore ${ }^{10}$ que, como en las anteriores entregas, no aparecen siempre en la película ( $y$, cuando lo hacen, es en los créditos finales, como mera justificación para su inclusión en la edición discográfica). El compositor fue Charlie Clouser, antes miembro de la banda Nine Inch Nails, de la cual se incluían ya algunos temas en la primera película de la saga, y colaborador en varios trabajos de Marilyn Manson entre 1994 y 2004. La música, en consecuencia, no se alejaba demasiado del espíritu de las dos primeras entregas.

Tras un tiempo irá a buscarlos a Arcadia, pero no logrará encontrarlos ni a ellos, ni al lugar. Solo encuentra a Claire, con la que llegará a una devastada ciudad de Los Angeles, uniéndose a unos pocos supervivientes que se refugian en la antigua cárcel. Allí descubrirán que Arcadia no es un lugar sino un barco, anclado ahora en la costa, frente a la ciudad. Se proponen llegar a él huyendo por las alcantarillas, enfrentándose de nuevo a zombis y mutantes. Una vez en el barco descubren que este es en realidad una trampa de Umbrella, con Wesker al mando, concebida para capturar supervivientes no infectados y poder experimentar con ellos. Liberan el barco, pero son atacados posteriormente por una flota de helicópteros comandada por Jill Valentine. Alice será capturada y recluida en una antigua base de submarinos en el Estrecho de Kamchatka. Allí es ayudada soprendentemente por Wesker, que envía un comando para rescatarla y a Ada Wong: el cambio de actitud de Wesker se debe a que ahora la necesita para salvar a la humanidad, ya que los únicos supervivientes que quedan están sitiados en la Casa Blanca. El Virus-T se les ha escapado de las manos, y Alice es la única que puede iniciar el principio del fin.

7 Roadrunner Recors (creado en 1980 en los Países Bajos con el nombre de Roadracer Records) se dedicó inicialmente a importar música metal norteamericana a Europa, siendo el distribuidor de los primeros álbumes de Metallica en los países escandinavos. Han editado o importado discos de Deicide, Sepultura, Slipknot (con los que obtuvieron su primer disco de platino en 2000) y es uno de los sellos especializados en metal más importante que existe.

8 El mismo subtítulo aclaratorio ostentaba la edición de la banda sonora de la segunda película: Resident Evil. Apocalipsis.

9 Entre otros, temas de Saliva, Depeche Mode, Rammstein, Adema y Static X.

10 De Shadows Fall, Fightstar, The Bled, It Dies Today, Poison the Well, Chimaira, Bayside, etc. 
En la cuarta entrega (Resident Evil. Ultratumba, 2010), sin embargo, se optó por encargar directamente una banda sonora a Tomandandy, mucho más electrónica. ${ }^{11}$ Los compositores declaraban a BSOSpirit:

Paul [se refieren al director Paul W.S. Anderson] quería algo totalmente nuevo. Quería renovar la saga, así que no quería ninguna referencia a las partituras de las películas anteriores o a las bandas sonoras de los videojuegos. Sugirió no utilizar ninguna orquesta, y por ahí es por donde empezamos, y la voz de la película surgió a partir de ahí. [...] La idea principal fue la de no utilizar ningún elemento orquestal en la película, para encontrar una paleta de sonidos nuevos para la partitura de la película y, como resultado, actualizar la franquicia (Doncel, 2010).

Pero ¿por qué este cambio de estrategia a medio recorrido?

En 2004 el videojuego Resident Evil 4 arrasó, superando con creces las unidades vendidas respecto a las entregas inmediatamente anteriores, que iban dibujando una curva descendente preocupante. La quinta entrega del videojuego (2009) la superó todavía más, batiendo records: ${ }^{12}$ se consolidaba un cambio de orientación hacia una mayor acción, intentando captar otro tipo de jugadores, más cercanos a juegos de acción como Call of Duty, por ejemplo, y alejándose del survival terror. Los responsables de las películas tomaron buena nota de este cambio de orientación, y lo aplicaron a sus films.

Como señalan Àngel Ferrero y Saúl Roas (2011), el zombi es un reflejo de un ser humano gregario que vive al margen de la sociedad. De ahí que podamos ver en el uso del metal en las tres primeras películas de Resident Evil (en adelante ER) esa metáfora de marginalidad, de pequeño grupo identitario... Como afirma Martínez (2003:103-104), el heavy metal es, además, una música asociada por lo común a la masculinidad y son pocas las intérpretes femeninas de este estilo musical, así como del rap o el techno, en comparación con sus colegas masculinos. En cuanto al consumo, tanto del metal como de los videojuegos, la balanza se decanta con menos peso hacia la testosterona, pero sin permitir todavía una paridad ${ }^{13}$, aunque la aparición de la Wii inició un cierto cambio de tendencia en este sentido. Si tomamos en consideración a Walser (1993:161-162), el metal ha desarrollado a menudo discursos de victimización masculina y androginia. Una de las más exitosas representaciones de la mujer en el metal es la femme fatale, que atrapa, traiciona o destruye al hombre. Al margen de

11 Aunque se mantiene algún bloque especialmente cercano al metal, como "Axeman", que suena durante la lucha entre Alice, Claire y el mutante, en las duchas de la prisión de Los Angeles. Y en la misma película suena "The Outsider (Apocalypse mix)" de Danny Lohner (de la banda de metal A Perfect Circle), que aparece en la batalla final contra Wesker y, como no podría ser de otro modo, al final de los créditos; y en la siguiente película, se opta por combinar la sonoridad electrónica de Bassnectar con la voz de Chino Moreno (cantante del grupo de metal alternativo Deftones) que interpreta "Hexes", de nuevo sólo en los créditos finales.

12 Los datos aportados por VGCharts, teniendo en cuenta solo los títulos principales de la saga son los siguientes (en millones de unidades vendidas a nivel mundial): Resident Evil (5'05), Resident Evil 2 (6'71), Resident Evil 3 (3'79), Resident Evil 4 (7'51), Resident Evil 5 (8,37) y Resident Evil 6 (4'48). Si añadiésemos los datos de las distintas reediciones, remakes y similares, no encontraríamos ventas superiores al millón y medio de unidades excepto en Resident Evil. Code: Veronica (2'40) o Resident Evil. Director's Cut (3'95)

13 Según los datos extraídos de la Asociación de Distribuidores y Editores de Software de Entretenimiento, en lo relativo a los videojuegos. 
las letras de los temas contenidos en las tres primeras películas de $R E_{1}{ }^{14}$ no podemos obviar que la protagonista de las cinco entregas es Alice, un personaje con toques andróginos, que mezcla la feminidad de su belleza con la masculinidad de sus acciones. Alice sería la femme fatale de RE, que atrapa, traiciona y destruye, en este caso, al zombi.

Las dos últimas (de momento) películas de la saga, inciden más en la acción y en la tecnología, con una ambientación más aséptica, cercana a Matrix (1999), menos gore y con menos zombis. A una percepción general que establece una convergencia cultural conceptual entre la música electrónica y estos elementos, sumemos lo dicho por Joan Pons: "De la misma manera que la cultura techno había adoptado como antecedentes obras del pasado que en su día, y a priori, nada tenían que ver con ella (recordemos: THX 1138, Tron...), también se buscaron conexiones similares en el presente" (Pons, 2008:214). Y, a continuación, se plantea unas dudas que podríamos adoptar como propias:

¿Es Final Fantasy (Hirnobo Sakaguchi y Moto Sakakibara, 2001) un film de la generación techno? ¿Y qué hay de los nuevos mundos paralelos estilo Matrix (Hermanos Wachowski, 1999), que sólo parecen posibles, al menos con esa apariencia, gracias a los avances de la tecnología y las apropiaciones de la filosofía cyberpunk de William Gibson? ¿Son techno o no? Y cuando la electrónica es ya la música del presente, ¿sigue siéndolo también del futuro? Es decir, ¿se tocan con la plástica de la electrónica obras de ciencia-ficción como Cube (Vincenzo Natali, 1997) y Gattaca (Andrew Niccol, 1997), o incluso ciertas piezas de dibujo hiperfuturista del anime? ¿Es Pi (Darren Aranofsky, 1998) una película afín a la electrónica porque su banda sonora sí lo es? (Pons, 2008:215).

Solo nos cabe añadir que los tópicos no existen porque sí, y que esta convergencia cultural conceptual entre la música electrónica y ciertos elementos "de futuro tecnológico" los hallamos ya desde películas como Planeta prohibido (Forbbiden Planet, 1956. Fred M. Wilcox), un film de ciencia ficción ambientado en un lejano planeta, con música electrónica de Bebe y Louis Barron.

\section{CONCLUSIONES}

En RE se da un claro caso de sinergia que, como bien define Barron (2003:150): "In this context, synergy is that practice by which media products can be utilised to advertise or support other media products". En las tres primeras películas de la saga encontramos al menos una doble edición discográfica: por un lado el CD con las canciones (no todas pertenecientes a la película), y por otro el que contiene la música instrumental original (vid. Tabla 3). Esta práctica, inaugurada con Batman en 1992, tiene entre otras motivaciones (Barron, 2003:154), el aprovechamiento del fenómeno fandom como comunidad social (y subcultural) alternativa, ya que es potencialmente muy rentable: son consumidores informados, que pueden comprar una banda sonora con un nuevo tema de su intérprete favorito, independientemente de su relación con la propia película como espectadores. Pero Barron también tiene claro que este aprovechamiento es mutuo: "Both film and musician can benefit equally from the combinations of popular music and film; synergistic practices benefits that are not merely uni-directional" (2003:160-161). ${ }^{15}$ Si la continua audición (entendamos emisión radiofónica o

14 Por cierto, censuradas en sus ediciones discográficas.

15 Acerca de estas prácticas sinérgicas en el uso de la música popular en el cine, recomendamos la lectura de la obra de Smith (1998), sobre todo los capítulos 3 y 8. 
TV, del disco y, desde hace relativamente pocos años, descarga de video-clips en la red) de unos temas puede contribuir al éxito del film, un film de éxito puede incentivar la venta de discos, así como el ingreso por derechos de reproducción. El fenómeno no es nuevo, y tiene su origen en el inesperado éxito del tema de El tercer hombre (1949, The Third Man, Carol Reed) de Anton Karas, hasta ese momento un desconocido músico húngaro, y sobre todo de la balada para Solo ante el peligro (1952, High Noon, Fred Zinneman) de Dimitri Tiomkin. ${ }^{16}$ Pasados más de sesenta años, la fórmula parece seguir funcionando.

Las sucesivas ediciones discográficas de RE han priorizado la composición original abandonando la inclusión de temas ajenos al film pero "inspirados en", y buscando la complicidad con el nuevo consumidor, aunque sin perder al antiguo, manteniendo ciertos guiños con el mismo con pinceladas de metal, aunque fuese forzando su inclusión en los créditos finales, como último reducto. Si en un principio hubo una cierta segmentación del mercado, a partir de la cuarta película el nicho de mercado al cual se dirigía había variado, y se alejaba del espíritu original del juego, lo cual motivó cierto desencanto en los más fieles seguidores de RE. De hecho, posiblemente los consumidores primigenios de $R E$, tanto del videojuego como de sus subproductos, dejaron incluso de ser un nicho de mercado. Del survival horror se pasó al film de acción, con una presencia casi anecdótica de zombis y mutantes, que perdían protagonismo, en pro de una mayor tecnofilia y acción, que conectaba con sectores más amplios de esos nativos digitales que estaban en plena adolescencia cuando apareció el primer videojuego de la saga (1996), pero que habían ido creciendo, y con las nuevas hornadas de la Generacion Net, que parece no poder sobrevivir sin una pantalla (o más de una) a su disposición.

Mientras el valor de marca de la franquicia parece inmutable a lo largo de los años, el público al cual se dirige parece no ser el mismo, a tenor de los resultados creativos, y la música ha sufrido una mutación desde el metal hasta la electrónica industrial. ¿Quizás esté infectada también por el Virus-T?

\section{BIBLIOGRAFÍA}

BARRON, Lee. "'Music Inspired By...': The Curious Case of the Missing Soundtrack", en Inglis, Ian, Popular Music and Film, Londres / Nueva York, Wallflower, 2003, pp. 148-161.

COLLINS, Karen. Game Sound. An introduction to the History, Theory, and Practice of Video Game Music and Sound Design, Cambridge / Londres, The Mit Press, 2008.

DONCEL, David y FERNÁNDEZ, Fernando. Entrevista a Tomandandy, 2010. Web BSOSpirit. Disponible en http://www.bsospirit.com/entrevistas/tomandandy.php (consulta: 21.01.2014)

FERRERO, Àngel; ROAS, Saúl. "El zombi como metáfora contracultural", en Nómadas. Revista crítica de ciencias sociales y jurídicas, vol. 32, n 4, 2011. Disponible en http://dx.doi. org/10.5209/rev_NOMA.2011.v32.n4.38076 (consulta: 20.01.2014)

HAHN, M.S. Video play pathways for females: developing theory. M. of Sc. Thesis de la Cornell University, 2006.

Disponible en https://ecommons.library.cornell.edu/bitstream/1813/3284/1/FINALTHESIS. pdf (consulta: 25.02.2014)

HAYWARD, Philipp (ed.). Terror tracks: music, sound and horror cinema, Londres, Equinox, 2009.

16 La historia del fenómeno y sus circunstancias puede seguirse en Smith (1998: 45-68) 
MARTÍNEZ, Silvia. "Decibelios y testosterona. Una aproximación a las imágenes de género en el rock y el heavy metal", Dossiers Feministes, n 7, 2003, pp. 101-117.

NIEDENTHAL, Simon. "Patterns of Obscurity: Gothic Setting and Light in Resident Evil 4 and Silent Hill 2", en Perron, Bernard (ed.). Horror Video Games: Essays on the Fusion of Fear and Play, Mc Farland \& Company, Inc., 2009, pp. 168-180. Disponible en http://dspace. mah.se/handle/2043/12772 (consulta: 15.01.2014)

PONS, Joan. "Ciencia ficción, raves y bajones. Música techno y cine", en Guillot, Eduardo (coord.) ¡Rock, acción! Ensayos sobre cine y música popular. Valencia, Avantpress, 2008, pp. 205-217.

SMITH, Jeff. The Sounds of Commerce. Marketing Popular Film Music. Nueva York, Columbia UP, 1998.

URBINA, S., RIERA, B., ORTEGO, J.L. y GIBERT, S., "El rol de la figura femenina en los videojuegos", Edutec: Revista electrónica de tecnología educativa, $n^{\circ}$ 15, 2002. Disponible en: http:// edutec.rediris.es/Revelec2/revelec15/santos.pdf (consulta: 24.02.2014)

WALSER, Robert. "Forging Masculinity: Heavy-Metal Sounds and Images of Gender", en Frith, Simon [et al.] (ed.) Sound and Vision. The Music Video Reader. Londres, Routledge, 1993, pp. 153-181.

WHALEN, Zach. "Case Study: Film Music vs. Video-Game Music: The Case of Silent Hill", en Sexton, Jamie (ed.). Music, Sound and Multimedia: From the Live to the Virtual, Edinburgh UP, 2007, pp. 68-84.

\section{OTRAS FUENTES}

a) Bases de datos online, webs corporativas y foros

Absolute-Video-Games http://www.absolute-video-games.com/ (última consulta: 03.04.2014) Capcom Database http://capcom.wikia.com/wiki/Capcom_Database (última consulta: 28.03.2014) Moby Games http://www.mobygames.com (última consulta: 28.03.2014)

Resident Evil Center. http://www.residentevilcenter.net/ (última consulta: 03.04.2014)

Resident Evil forum. http://residentevil.org/ (última consulta: 03.04.2014)

VGCharts. Video Game Charts, Game Sales, Top Sellers, Game Data. http://www.vgchartz. com/ (última consulta: 20.03.2014)

VGMdb [Video Game Music Database]. http://vgmdb.net/db/main.php (última consulta: 03.04.2014)

Web de la Asociación Española de Distribuidores y Editores de Software de Entrenimiento. http://www.adese.es (última consulta: 20.03.2014)

Web oficial de Capcom. http://www.capcom.co.jp/ir/english/ (última consulta: 28.03.2014)

b) Entrevistas

Scoring Resident Evil. (Jeffrey Schwarz, 2002) [extra en DVD Special Edition y Deluxe Edition] Charlie Clouser RESIDENT EVIL EXTINCTION Film Score Composer Interview. (David Huffman, 2007). Disponible en http://www.youtube.com/watch?v=fD9JjX-vhoo (consulta: 15.02.2014) 


\section{ANEXO}

\section{Tabla 1. Largometrajes basados en películas, y su referente en el videojuego, con indicación de sus correspondientes músicas ${ }^{17}$.}

\begin{tabular}{|c|c|c|c|}
\hline Película (año) & Músicas $^{18}$ & Videojuego (año) & Músicas $^{19}$ \\
\hline $\begin{array}{l}\text { Super Mario Bros (1993, Annabel } \\
\text { Jankel, Rocky Morton) }\end{array}$ & $\begin{array}{l}\text { BSO: Alan Silvestri. } \\
\text { Canciones: Roxette, Queen, } \\
\text { Megadeth, Extreme, Us3, Joe } \\
\text { Satriani, Marky Mark, Charles \& Eddie, } \\
\text { George Clinton \& The Goombas, } \\
\text { Divinyls (cover de Roxy Music) }\end{array}$ & $\begin{array}{l}\text { Super Mario } \\
\text { [saga] (1985-2013) }\end{array}$ & $\begin{array}{l}\text { BSO: Koji Kondo, Kazumi } \\
\text { Totaka, Irozaku Tanaka, Mahito } \\
\text { Yokota, Ryo Nagamatsu. }\end{array}$ \\
\hline $\begin{array}{l}\text { Doble Dragón (Double Dragon, } \\
\text { 1994, James Nickson) }\end{array}$ & $\begin{array}{l}\text { BSO: Jay Ferguson. } \\
\text { Canciones: Coolio, Dink, Crystal } \\
\text { Waters, Darryl D’Bonneau, Head } \\
\text { Boys, Steve B, The Farm. }\end{array}$ & $\begin{array}{l}\text { Double Dragon [saga] (1987- } \\
\text { 2009) }\end{array}$ & $\begin{array}{l}\text { BSO: Kazunaka Yamame, Kiyomi } \\
\text { Kataoka, Chiaki lizuka, Reiko } \\
\text { Uehara, Fumio Suzuki, Jake } \\
\text { Kaufman. }\end{array}$ \\
\hline $\begin{array}{l}\text { Street Fighter. La última batalla } \\
\text { (Street Fighter. 1994, Steven E. } \\
\text { de Souza) }\end{array}$ & $\begin{array}{l}\text { BSO: Graeme Revell. } \\
\text { Canciones: Ice Cube, M.C.Hammer, } \\
\text { Ahmad, Ras Kass and Saafir; Nas, } \\
\text { Paris, Rally Ral, Hammer, Public } \\
\text { Enemy, World Beaters, LL Cool J, } \\
\text { The Pharcyde, Angélique Kidjo. }\end{array}$ & $\begin{array}{l}\text { Street Fighter [saga] (1987 } \\
\text { a 2011) }\end{array}$ & $\begin{array}{l}\text { BSO: Yoshihiro Sakaguchi, } \\
\text { Ryoko Shinorhara, T.Komuro, } \\
\text { Capcom Sound Team Alpha } \\
\text { Lyla, Yuki Iwai, Tetsuya Shibata, } \\
\text { Hideki Okugawa, Isao Abe, } \\
\text { Takayuki Iwai. }\end{array}$ \\
\hline $\begin{array}{l}\text { Mortal Kombat (1995, Paul W. S. } \\
\text { Anderson) }\end{array}$ & $\begin{array}{l}\text { BSO: George S. Clinton. } \\
\text { Canciones: Gravity Kills, KMFDM, } \\
\text { Psykosonik, Traci Lords, Orbital, } \\
\text { Sister Machine Gun, Fear Factory, } \\
\text { Napam Death, Mutha's Day Out, } \\
\text { Stabbing Westward, }\end{array}$ & $\begin{array}{l}\text { Mortal Kombat [saga] (1992 } \\
\text { a 1995) }\end{array}$ & $\begin{array}{l}\text { BSO: Allister Brimble, Chris } \\
\text { Brayman, Mark Ganus. } \\
\text { Canciones: interpretadas por } \\
\text { The immortals. }\end{array}$ \\
\hline $\begin{array}{l}\text { Wing Commander (1999, Chris } \\
\text { Roberts) }\end{array}$ & $\begin{array}{l}\text { BSO: David Arnold, Kevin Kiner. } \\
\text { Canciones: Cuba (Chris Andrews \& } \\
\text { Ashley Bates), Thievery Corporation } \\
\text { (Rob Garza, Eric Hilton). }\end{array}$ & $\begin{array}{l}\text { Wing Commander [saga] } \\
(1990-2007)\end{array}$ & $\begin{array}{l}\text { BSO: Mark Knight, George } \\
\text { Alistair Sanger, Martin Galway, } \\
\text { David Govett, Nenad Vugrinec, } \\
\text { Dana Glover, George Oldziey. }\end{array}$ \\
\hline $\begin{array}{l}\text { Lara Croft: Tomb Raider (2001, } \\
\text { Simon West) }\end{array}$ & $\begin{array}{l}\text { BSO: Graeme Revell. } \\
\text { Canciones: Fatboy Slim, U2, Moby, BT, } \\
\text { Outkast, The Chemical Brothers, Fluke, } \\
\text { Delerium, Vas, Bosco, Moby, Missy } \\
\text { Elliot, Leftfield, Oxide \& Neutrino, } \\
\text { Craig Armstrong, Groove Amanda, } \\
\text { Basement Jaxx, Gary Numan. }\end{array}$ & $\begin{array}{l}\text { Tomb Raider [saga](1996- } \\
\text { 2012) }\end{array}$ & $\begin{array}{l}\text { BSO: Martin Iveson, Nathan } \\
\text { McCree, Peter Connelly. }\end{array}$ \\
\hline $\begin{array}{l}\text { Final Fantasy. La fuerza interior } \\
\text { (Final Fantasy: The Spirits Within. } \\
\text { 2001, Hironobu Sakaguchi) }\end{array}$ & $\begin{array}{l}\text { BSO: Elliot Goldenthal. } \\
\text { Canciones: Lara Fabian, L'Arc-en- } \\
\text { Ciel. }\end{array}$ & $\begin{array}{l}\text { Final Fantasy [saga] (1987- } \\
\text { 2013) }\end{array}$ & BSO: Nobuo Uematsu \\
\hline $\begin{array}{l}\text { Lara Croft Tomb Raider. El agua } \\
\text { de la vida (Lara Croft Tomb } \\
\text { Raider: The Cradle of Life) (2003, } \\
\text { Jan de Bort) }\end{array}$ & $\begin{array}{l}\text { BSO: Alan Silvestri. } \\
\text { Canciones: Davey Brothers, Filter, } \\
\text { Alexandra Slate, P.O.D., The Dandy } \\
\text { Warhols, Saliva, Lunatic Calm, } \\
\text { Moby, The Crystal Method, Korn, } \\
\text { Kassabian, Sage Guyton \& Jeremy } \\
\text { Wakefield, Davey Brothers, Sloth, 3rd } \\
\text { Strike, Nadirah 'Nadz' Seid. }\end{array}$ & $\begin{array}{l}\text { Tomb Raider [saga] (1996- } \\
\text { 2014) }\end{array}$ & $\begin{array}{l}\text { BSO: Martin Iveson, Nathan } \\
\text { McCree, Peter Connelly. }\end{array}$ \\
\hline
\end{tabular}

17 Se excluyen las distintas entregas de Resident Evil, que se detallarán en la Tabla 2.

18 De las canciones se indican los intérpretes de los temas y no los compositores y/o letristas.

$19 \mathrm{Se}$ indican todos los compositores que han intervenido a lo largo detodo el ciclo de vida de la saga. La gran cantidad de compositores que participan en cada proyecto, no siempre responden a una presunta complejidad del mismo, sino que en muchas ocasiones, cada compositor se encarga de la composición (a medida) de cada una de las versiones para las distintas plataformas (DOS, Amiga, NES, etc.) 


\begin{tabular}{|c|c|c|c|}
\hline $\begin{array}{l}\text { House of the Dead (2003, Uwe } \\
\text { Boll) }\end{array}$ & $\begin{array}{l}\text { BSO: Reinhard Besser. } \\
\text { Canciones: Codetrasher, Rey } \\
\text { Thomas, Black Tiger, Okio, The } \\
\text { Horror Boogies. }\end{array}$ & $\begin{array}{l}\text { The House of the Dead [saga] } \\
\text { (1997 a 2011) }\end{array}$ & BSO: Tetsuya Kawauchi \\
\hline $\begin{array}{l}\text { Alone in the Dark (2005, Uwe } \\
\text { Boll) }\end{array}$ & $\begin{array}{l}\text { BSO: Reinhard Besser, Oliver Lieb, } \\
\text { Bernd Wendlandt y Peter Zweier. } \\
\text { Canciones: Mnemic, Deathstars, } \\
\text { Nightwish, Neneh Cherry \& Youssou } \\
\text { N'Dour, The Supernatural Boogies, } \\
\text { Angelzoom. }\end{array}$ & $\begin{array}{l}\text { Alone in the Dark [saga] } \\
\text { (1992-2008) }\end{array}$ & $\begin{array}{l}\text { BSO: Philippe Vachey, Thierry } \\
\text { Desseaux, Jean-Sebastien } \\
\text { Rossbach, Jean-Luc Escalant, } \\
\text { Christian Morei, Laurent Paret } \\
\text { Canciones: En Alone in the } \\
\text { Dark: The New Nightmare (2001) } \\
\text { el tema principal lo interpretaba } \\
\text { Stewart Copeland. }\end{array}$ \\
\hline Doom (2005, Andrzej Bartkowiak) & $\begin{array}{l}\text { BSO: Clint Mansell. } \\
\text { Canciones: Nine Inch Nails, } \\
\text { Celldweller. }\end{array}$ & Doom [saga] (1993-2012) & BSO: Bobby Prince \\
\hline $\begin{array}{l}\text { Silent Hill (2006, Christophe } \\
\text { Gans) }\end{array}$ & $\begin{array}{l}\text { BSO: Jeff Danna, Akira Kamaoka (se } \\
\text { utiliza la música original del juego) } \\
\text { Canciones: Johnny Cash. }\end{array}$ & Silent Hill [saga] (1999-2012) & BSO: Akira Kamaoka \\
\hline $\begin{array}{l}\text { DOA: Dead or alive (2006, Cory } \\
\text { Yuen) }\end{array}$ & $\begin{array}{l}\text { BSO: Junkie XL. } \\
\text { Canciones: Joe Seabe, Laurie } \\
\text { Grant \& Pete Kulvicki; Jeffrey } \\
\text { Allen Freundlich, Gary Joseph } \\
\text { Romero \& Hogan Todd; Muff/ } \\
\text { Reez, Bodyrockers, Bitter:Sweet, } \\
\text { Yesking, Playgroup (con K.C. Flightt), } \\
\text { Oakenfold (con Ryan Tedder) }\end{array}$ & $\begin{array}{l}\text { Dead or alive [saga] (1996- } \\
\text { 2013) }\end{array}$ & BSO: Makoto Hosoi \\
\hline Hitman (2007, Xavier Gens) & $\begin{array}{l}\text { BSO: Geof Zanelli. } \\
\text { Canciones: interpretadas por Justice, } \\
\text { Muff \& Rezz, Gilberto Candido y } \\
\text { The Male Choir of Valaam Singing } \\
\text { Culture Institute. }\end{array}$ & Hitman [saga] (2000-2012) & BSO: Jesper Kyd, Pierre Földes. \\
\hline $\begin{array}{l}\text { En nombre del rey (In the Name } \\
\text { of the King: A Dungeon Siege } \\
\text { Tale. 2007, Uwe Boll) }\end{array}$ & $\begin{array}{l}\text { BSO: Jessica de Rooij. Henning Lohner. } \\
\text { Canciones: Blind Guardian, } \\
\text { Threshold, HammerFall. }\end{array}$ & $\begin{array}{l}\text { Dungeon Siege [saga] (2002- } \\
\text { 2011) }\end{array}$ & $\begin{array}{l}\text { BSO: Jeremy Soule, Julian } \\
\text { Soule, Crispin Hands. }\end{array}$ \\
\hline Far Cry (2008, Uwe Boll) & $\begin{array}{l}\text { BSO: Jessica de Rooij. } \\
\text { Canciones: Robert Beld, Richard } \\
\text { Smith, The Incredible Adventures Of } \\
\text { Billy And Max. }\end{array}$ & Far Cry [saga] (2004-2014) & $\begin{array}{l}\text { BSO: Power Glove, Brian Tyler, } \\
\text { Marc Canham. }\end{array}$ \\
\hline Max Payne (2008, John Moore) & $\begin{array}{l}\text { BSO: Marco Beltrami, Buck Sanders. } \\
\text { Canciones: Metsuo. }\end{array}$ & Max Payne [saga] (2001-2012) & $\begin{array}{l}\text { BSO: Tom Kingsley. } \\
\text { Canciones: Health, Emicida. }\end{array}$ \\
\hline $\begin{array}{l}\text { Street Fighter: la leyenda (Street } \\
\text { Fighter: The Legend of Chun-Li. } \\
\text { 2009, Andrzej Bartkowiak) }\end{array}$ & $\begin{array}{l}\text { BSO: Stephen Endelman. } \\
\text { Canciones: Ace Hood, One Block } \\
\text { Radius. }\end{array}$ & $\begin{array}{l}\text { Street Fighter [saga] (1987 } \\
\text { a 2011) }\end{array}$ & $\begin{array}{l}\text { BSO: Yoshihiro Sakaguchi, Ryoko } \\
\text { Shinorhara, T.Komuro, Capcom } \\
\text { Sound Team Alpha Lyla, Yuki Iwai, } \\
\text { Tetsuya Shibata, Hideki Okugawa, } \\
\text { Isao Abe, Takayuki Iwai. }\end{array}$ \\
\hline $\begin{array}{l}\text { Prince of Persia: las arenas del } \\
\text { tiempo (Prince of Persia: The } \\
\text { Sands of Time. 2010, Mike } \\
\text { Newell) }\end{array}$ & $\begin{array}{l}\text { BSO: Harry Gregson-Williams } \\
\text { Canciones: Alanis Morissette, Loga } \\
\text { Ramin Torkian. }\end{array}$ & $\begin{array}{l}\text { Prince of Persia [saga] (1989- } \\
\text { 2010) }\end{array}$ & $\begin{array}{l}\text { BSO: Francis Mechner, Jonelle } \\
\text { Adkisson, Mark Chosak, Romain } \\
\text { Gauthier, Mathieu Vachon, Inon Zur, } \\
\text { Stuart Chatwood, Steve Jablonsky, } \\
\text { Penka Kouneva, Tom Salta. }\end{array}$ \\
\hline $\begin{array}{l}\text { In the Name of the King 2: Two } \\
\text { Worlds (2011, Uwe Boll) }\end{array}$ & $\begin{array}{l}\text { BSO: Jessica de Rooij } \\
\text { Canciones: - }\end{array}$ & $\begin{array}{l}\text { Dungeon Siege [saga] (2002- } \\
\text { 2011) }\end{array}$ & $\begin{array}{l}\text { BSO: Jeremy Soule, Julian } \\
\text { Soule, Crispin Hands }\end{array}$ \\
\hline $\begin{array}{l}\text { Silent Hill: Revelación 3D (Silent } \\
\text { Hill: Revelation 3D. 2012, Michael } \\
\text { J. Bassett) }\end{array}$ & $\begin{array}{l}\text { BSO: Akira Yamaoka. } \\
\text { Canciones: Akira Yamaoka. }\end{array}$ & Silent Hill [saga] (1999-2012) & BSO: Akira Kamaoka. \\
\hline
\end{tabular}

20 Existe una segunda parte (House of the Dead 2) de 2005 estrenada directamente en un canal de TV por cable de EEUU. 
Tabla 2. Entregas del videojuego Resident Evil, con indicación de sus respectivos compositores.

\begin{tabular}{|c|c|c|c|}
\hline Videojuego & Plataformas $^{21}$ & Año ${ }^{22}$ & Autoría musical \\
\hline Resident Evil & $\begin{array}{l}\text { PS1, PC, Nintendo DS, SEGA Saturn, } \\
\text { Móvil }\end{array}$ & 1996 & $\begin{array}{l}\text { M on M inc. [Koichi Hiroki]/ Music Expedition Co. } \\
\text { Ltd. }{ }^{23} \text {, Makoto Tomozawa, Akari Kaida, Masami Ueda. }\end{array}$ \\
\hline Resident Evil. Director's Cut & PS1 & 1997 & Makoto Tomozawa, Akari Kaida, Masami Ueda. \\
\hline Resident Evil. Dual Shock Version ${ }^{24}$ & PS1 & $1997 ?$ & Mamoru Samuragochi. ${ }^{25}$ \\
\hline Resident Evil 2 & $\begin{array}{l}\text { PS1, GameCube, PC, Nintendo 64, } \\
\text { Game Boy Color, Dreamcast }\end{array}$ & 1998 & Masami Ueda, Shusaku Uchiyama, Shun Nishigaki. \\
\hline Resident Evil 3: Nemesis & $\begin{array}{l}\text { PS1, PS3, GameCube, PC, PSP, } \\
\text { Game Boy Color, Dreamcast }\end{array}$ & 1999 & Masami Ueda, Saori Maeda. \\
\hline Resident Evil Code: Veronica & $\begin{array}{l}\text { PS2, PS3, GameCube, Xbox, } \\
\text { Dreamcast }\end{array}$ & 2000 & Takeshi Mura, Hijiri Anze, Sanae Kasahara. \\
\hline Resident Evil: Survivor & PS1, PC & 2000 & Ichiro Kohmoto. \\
\hline Resident Evil: Gaiden & Game Boy Color & 2000 & Shahid Ahmad. \\
\hline Resident Evil Code: Veronica X & Dreamcast, PS2, GameCube & 2001 & Takeshi Mura, Hijiri Anze, Sanae Kasahara. \\
\hline Resident Evil Zero & GameCube, Wii, Dreamcast & 2002 & $\begin{array}{l}\text { Ichiro Kohmoto, Riyou Kinugasa, Ryoue Takagi, Shingo } \\
\text { Kataoka, Ayumu Murai, Takashi Honda, Seiko Kobuchi. }\end{array}$ \\
\hline $\begin{array}{l}\text { Resident Evil Survivor 2: Code } \\
\text { Veronica }\end{array}$ & PS2 & 2002 & [Ichiro Kohmoto ?] \\
\hline Resident Evil (remake) & GameCube, Wii & 2002 & $\begin{array}{l}\text { Shusaku Uchiyama, Misao Senbongi, Makoto } \\
\text { Tomozawa. }\end{array}$ \\
\hline Resident Evil: Dead Aim & PS2 & 2003 & $\begin{array}{l}\text { Nobuyoshi Sano } \\
\text { Canción: "Gun Shot" interpretado por Rize (suena en } \\
\text { los créditos finales) }\end{array}$ \\
\hline Resident Evil: Outbreak & PS2 & 2003 & $\begin{array}{l}\text { Akihiko Matsumoto, Tetsuya Shibata, Etsuko Yoneda, } \\
\text { Mitsuhiko Takano, Kento Hasegawa, Masato Kohda. }\end{array}$ \\
\hline Resident Evil: Outbreak File 2 & & 2004 & $\begin{array}{l}\text { Akihiko Matsumoto, Tetsuya Shibata, Etsuko Yoneda, } \\
\text { Mitsuhiko Takano, Kento Hasegawa. }\end{array}$ \\
\hline Resident Evil 4 & $\begin{array}{l}\text { PS2, PS3, Xbox, GameCube, Wii, } \\
\text { PC, Móvil }\end{array}$ & 2005 & $\begin{array}{l}\text { Misao Senbongi, Shusaku Uchiyama / Masami Ueda, } \\
\text { Saori Maeda (según CD) }\end{array}$ \\
\hline Resident Evil: Deadly Silence & Nintendo DS & 2006 & Mitsuhiko Takano. \\
\hline $\begin{array}{l}\text { Resident Evil: The Umbrella } \\
\text { Chronicles }\end{array}$ & PS3, Wii & 2007 & Masafumi Takada, Jun Fukuda. \\
\hline Resident Evil 5 & PS3, Xbox, PC & 2009 & $\begin{array}{l}\text { Kota Suzuki, Hideki Okugawa, Akihiko Narita, Seiko } \\
\text { Kobuchi, (música adicional: Wataru Hokoyama) }\end{array}$ \\
\hline
\end{tabular}

21 No se tienen en cuentas las versiones (once) que fueron creadas exclusivamente para dispositivos móviles, entre 2004 y 2011.

22 En ocasiones la aparición en el mercado de las distintas versiones, no es simultánea. Se indica aquí la primera fecha de comercialización.

23 En los créditos del juego aparecen estas dos "empresas" (?) como responsables de la música, así como de los temas del opening ("Terror") y el ending ("Still Dawn") No obstante, la edición discográfica (Biohazard Soundtrack Remix, 1996) contradice los créditos, atribuyendo ambos temas a Tomozawa. Esta es solo una muestra de la dificultad en la atribución de las autorías en la música para videojuegos.

24 Es en realidad una segunda versión de Resident Evil. Director's Cut, que apareció solo en Japón y Estados Unidos, sustituyendo la banda sonora original por otra, y otras novedades sobre todo técnicas. Incluía también secuencias del prototipo cancelado de Resident Evil 2 titulado Resident Evil 1.5

25 En realidad, en febrero de 2014 el compositor japonés Mamoru Samuragochi, conocido como el "Beethoven japonés" por su sordera, confesaba que llevaba veinte años simulando que componía, cuando en realidad tenía un "negro" aún sin identificar. Samuragochi había compuesto también en 1998 la Biohazard Simphony Op. 91 Crime and Punishement, inspirada en el videojuego. 


\begin{tabular}{|l|l|l|l|}
\hline $\begin{array}{l}\text { Resident Evil: The Darkside } \\
\text { Chronicles }\end{array}$ & PS3, Wii & 2009 & $\begin{array}{l}\text { [Shusaku Uchiyama, Takeshi Miura [Orquestador: } \\
\text { Yoshihisa Mirano. Director: Koji Haishima] }\end{array}$ \\
\hline Resident Evil: The mercenaries 3D & Nintendo 3DS, Móvil & 2011 & $\begin{array}{l}\text { Kota Suzuki, Ichiro Kohmoto, Yasumasa Kitagawa, } \\
\text { Shusaku Uchiyama, Misao Senbongi, Hideki Okugawa } \\
\text { Akihiko Narita Kazuki Kuriyama. }\end{array}$ \\
\hline Resident Evil: Revelations & PS3, Xbox, PC, Nintendo 3DS, Wii U & 2012 & Kota Suzuki, Ichiro Kohmoto, Takeshi Miura. \\
\hline $\begin{array}{l}\text { Resident Evil: Operation Raccoon } \\
\text { City }\end{array}$ & PS3, Xbox, PC & 2012 & Shusaku Uchiyama. \\
\hline Resident Evil 6 & PS3, Xbox, PC & $\begin{array}{l}\text { Akihiko Narita, Akiyuki Morimoto, Azusa Kato } \\
\text { Kota Suzuki, Thomas Parish, Laurent Ziliani, Kota Suzuki, } \\
\text { Daniel Lindholm, Sebastian Schwartz. } \\
\text { Canción: "At the End of a Long Escape" (Kieron Cashell). }\end{array}$ \\
\hline
\end{tabular}

\section{Tabla 3. Datos (estreno, recaudación y músicas) de los largometrajes de la saga Resident Evil. ${ }^{26}$}

\begin{tabular}{|c|c|}
\hline elícula & BSM \\
\hline $\begin{array}{l}\text { Resident Evil } \\
\text { (2002, Paul W.S.Anderson) } \\
\text { Estreno mundial: } 15.03 .2002 \\
\text { Recaudación primer fin de semana (EUA): } \\
\text { 17.707.106\$(17.03.2002) (2.528 pantallas) }\end{array}$ & $\begin{array}{l}\text { BSO: Marco Beltrami, Marilyn Manson, Kevin Manthei (música adicional sin } \\
\text { acreditar), } \\
\text { Canciones: "Existence" por Frontline Assembly, "Fist Fuck" por Nine Inch Nails, } \\
\text { "Cyanide 2600" por Spineshank, "Wall of Death", por Apollo 440, "Torched" } \\
\text { por Frontline Assembly, "My Plague (New Abuse Mix)" por Slipknot, "Something } \\
\text { Told Me" por Coal Chamber, "Invisible Wounds (Dark Bodies)" por Fear Factory, } \\
\text { "Supplementary Soundscapes" por Junkie XL. } \\
\text { Ediciones discográficas } \\
\text { CD (canciones y cuatro cortes instrumentales de Marylin Manson): Roadrunner } \\
\text { Records RR8450-2 (12.03.2002) } \\
\text { CD (partitura original Beltrami): Addicted Artists Association (¿?.¿?.2002) contiene } \\
\text { también cortes de las dos siguientes películas de la saga. } \\
\text { CD single (incluye el tema "My plague (New Abuse Mix") de Slipknot: Roadrunner } \\
\text { Records RR-2045 } 3 \text { (2002) }\end{array}$ \\
\hline $\begin{array}{l}\text { Resident Evil: Apocalipsis } \\
\text { (2004, Resident Evil: Apocalypse, Alexar } \\
\text { Estreno mundial: } 10.09 .2004 \\
\text { Recaudación primer fin de semana (EUA } \\
23.036 .273 \$ \text { (12.09.2004) (3.284 pantall }\end{array}$ & $\begin{array}{l}\text { BSO: Jeff Danna, Elia Cmiral (música adicional sin acreditar) } \\
\text { Canciones: "No Way Out", "In the War Zone" y "Run for Your Life" (Elia Cmiral), } \\
\text { por Elia's Lonely Friends Band, "Nymphetamine" por Cradle of Filth, "Digging } \\
\text { Up the Corpses" por DevilDriver, "The End of Heartache" por Killswitch Engage, } \\
\text { "Vermilion" por Slipknot. } \\
\text { Ediciones discográficas } \\
\text { CD (canciones): Roadrunner Records RR } 8230-2 \text { (31.08.2004) } \\
\text { CD (partitura Danna): Varese Sarabande 302 } 0666162 \text { (28.09.2004)27 } \\
\text { CD (partitura Cmiral): promo con siete cortes (2004) }\end{array}$ \\
\hline $\begin{array}{l}\text { Resident Evil: Extinción } \\
\text { (2007, Resident Evil: Extinction, Russell Mulcahy) } \\
\text { Estreno mundial: } 21.09 .2007 \\
\text { Recaudación primer fin de semana (EUA): } \\
\text { 23.678.580\$ (23.09.2007) (2.828 pantallas) }\end{array}$ & $\begin{array}{l}\text { BSO: Charlie Clouser } \\
\text { Canciones: "In-A-Gadda-Da-Vida" por Iron Butterfly, "White Rabbit" por Collide, } \\
\text { "My World" por Emigrate, "Contagious" por Searchlight. } \\
\text { Ediciones discográficas } \\
\text { CD (canciones)28: Lakeshore Records LKS } 339482 \text { (18.09.2007) } \\
\text { CD (partitura Clouser) Lakeshore Records LKS } 339752 \text { (18.12.2007) }\end{array}$ \\
\hline
\end{tabular}

26 Se excluyen las películas de animación Resident Evil: Degeneración (Resident Evil: Degeneration, 2008) y Resident Evil: La maldición (Resident Evil: Damnation, 2012), ambas dirigidas por Makoto Kamiya.

27 Existe una edición alemana: Colosseum VSD-6616 (28.09.2004)

28 Incluye cuatro temas instrumentales de Charlie Clouser. Existe una edición alemana: Bodogmusic 0180365BDM (28.09.2007) 


Resident Evil: Ultratumba
(2010, Resident Evil: Afterlife, Paul W.S. Anderson)
Estreno mundial: 10.09.2010 (en Japón se hizo la
premiere el 02.09.2010)
Recaudación primer fin de semana (EUA):
26.650.264\$ (12.09.2010) (3.203 pantallas)
Resident Evil 5: la venganza
(2012, Resident Evil: Retribution, Paul W.S.
Anderson)
Estreno mundial: 14.09 .2013 (en Japón se hizo la
premiere el 03.09 .2013 y en varios países se estrenó
los días 12 y 13 de septiembre)
Recaudación primer fin de semana (EUA):
$21.052 .227 \$$ (16.09.2012) (3.012 pantallas)

BSO: Tomanandy

Canciones: "The Outsider (Apocalypse mix)" por A Perfect Circle.

Ediciones discográficas

CD (todo): Milan Records M2-36532 (EUA: 28.09.2010)

CD (todo): Milan Records 399 338-2 (EU: 13.09.2010)

BSO: Tomanandandy

Canciones: "Hexes" (feat. Chino Moreno) por Bassnectar [Lorin Ashton]

\section{Ediciones discográficas:}

CD (todo): Milan Records M2-36592 (EUA: 11.09.2013)

CD (todo): Warner Japan WPCR-14829 (¿?)

a (EUA):

21.052.227\$ (16.09.2012) (3.012 pantallas) 